\title{
Compliance with Company and Allied Matters Act (CAMA) Evincing Financial Reporting Quality Impact on Performance of Small and Medium Enterprises (SMEs) in Nigeria
}

\author{
Mohammed DANJUMA (PhD) Peter TERU (PhD) \\ Musa JERRY (PhD) Rukaiyatu Adamu \\ Department of accounting, Adamawa State University, PMB 25, Mubi, Adamawa State, Nigeria
}

\begin{abstract}
This study is on the compliance with regulatory framework by Small and Medium Enterprises (SMEs) in Nigeria evincing financial reporting quality impact on firm performance. The design is an exploratory survey employing structural equation modelling in model specification. The empirical analysis of this study went through exploratory factor analysis (EFA) and then confirmed by confirmatory factor analysis (CFA). This study examined the impact of compliance with companies and allied Matters Act through financial reporting quality on performance of SMEs in Nigeria. The outcome revealed that the Financial Reporting Quality (exogenous variables) accounted for 39\% while the Firm Performance (endogenous variables) accounted for $61 \%$ of the total variance. Thus, the Squared Multiple Correlations (SMC) fraction result confirmed that financial reporting quality has direct relationship with SMEs performance. Thus, Financial Reporting Quality (FRQ) impact on firm performance at $(\beta=0.875)$ is significant. The study recommends that since FRQ is having a direct and significant relationship with SMEs performance the need for enforcing compliance to statutory and regulatory framework on SMEs by SMEDAN, CBN and all other stakeholders is necessary.
\end{abstract}

Keywords: compliance, reporting quality, performance, SMEs, Nigeria.

DOI: $10.7176 / \mathrm{RJFA} / 10-6-08$

Publication date:March $31^{\text {st }} 2019$

\section{Introduction}

Regulatory laws are guidelines that oversee the operations of Small and Medium Enterprises (SMEs). These guidelines are usually promulgated by government regulators or international groups to protect stakeholders, maintain orderly markets and encourage financial stability. The variety of regulatory accomplishments can include setting minimum standards for best practice in product orientation, production and marketing, making consistent assessments, investigating and prosecuting misconduct, Organization for Economic Co-operation and Development (OECD, 2010). As of the preceding, regulatory laws incorporate a set of rules evolved by regulatory bodies; government or private, to guide the operations of corporations. These rules might have the legislative support or may perhaps be a pronouncement by the relevant body to be strictly adhered to by SMEs. Contained by the framework of financial reporting, regulatory laws entail of outlines issued in form of enactments, guidelines, and standards to be followed by enterprises when preparing financial statements. The procedures as directed by regulatory agency regularly make available an option for entities to choose which technique or basis of accounting SMEs have a preference. Cutting-edge SMEs taking advantage of this, the organizations eventually overwhelmed the regulatory agency such that the focus of the objective of regulation (promoting public's interest) is shifted to protecting the interest of the entities.

Compliance by and large covers substances such as observing proper standards of market conduct, reporting, managing conflicts of interest, treating customers fairly, and ensuring adherence to laid down procedures. On the whole, enterprises are to comply with primary regulation, guidelines, and standards issued by legislators, market conventions, codes of practice promoted by Small and Medium Development Agency of Nigeria (SMEDAN), and internal codes of conduct. The Companies and Allied Matters Act, 2004 as amended is a major statutory framework that guides the activities and operations of Companies in Nigeria. It regulates virtually all aspects of Companies activities in Nigeria, including incorporation, management, and other issues. SMEs comply most importantly with Companies and Allied Matters Act (CAMA) 1990 as amended 2004 and Central Bank of Nigeria (CBN) Prudential Guidelines.

The CAMA has provisions relating to companies financial reporting practice. Iyoha and Jimoh (2011) described CAMA as the Generally Accepted Accounting Principle (GAAP), within the Nigeria reporting environment. The basic requirement relating to corporate financial reporting is contained in Part XI-Financial Statements and Audit. Sections 331-356 of CAMA 2004, relate to financial statements while sections 357 to 369 to Audit. Section 331 compels all companies to keep accounting records. These accounting records should contain all matters in respect of all receipt and expenditure. The accounting records should be sufficient to show and disclose with reasonable accuracy, at any time, the financial position of the company. Section 332 states that the accounting records should be kept in a registered office or such other places fit by the directors, subject to 
subsection 2 of the same section which is in respect of the disposal of records under winding up rules. Section 333 deals with penalties for non-compliance with the provisions of sections 331 and 332 of the CAMA. Section 334 requires directors of every company to prepare financial statements in respect of each year of the company. Section 334 (2) states that financial statements should include: statement of accounting policies; the statement of financial position as at the last date of the year; a statement of profit or loss account or, in the case of company not trading for profit, an income and expenditure account for the year; note on the account; the auditor's report; the directors report; a statement of source and application of funds (now replaced by statement of cash flow since 1997); a value-added statement of the year; a five year financial summary; and for holding company, a group financial statement. Section 334 (3) exempts private companies from preparing a statement of accounting policies, a statement of source and application of funds (now replaced by a statement of cash flow since 1997), a value-added statement of the year and for holding company, a group financial statement. Section 335 states the form and content of individual financial statements. It requires the financial statements of a company to comply with the requirements of Schedule 2 to the Act (as far as applicable) and with the accounting standard as laid down from time to time by the Nigerian Accounting Standard Board now the Financial Reporting Council of Nigeria (FRCN).

Section 340-341 deal with the disclosure of loans in favor of directors and connected persons in accordance with Part I and Part II of Schedule 4 of the Act (so far as applicable). Part I of the Schedule 4 is in relating to disclosure of transactions, arrangements, and agreements mentioned therein, including loans, quasi-loans and other dealing in favor of the director. Part II of Schedule 4 is regarded as transactions, arrangements, and agreements made by the company or subsidiary of it for persons who at any time during the year were officers of the company but not directors. Section 342 requires every company to prepare with respect to each year a report by the directors in accordance with Schedule 4 of the Act. It also states penalties for non-compliance. Section 343 - 349 deal with the procedure for completion of financial statements. Section 343 requires two of the directors of the company to sign the statement of financial position and documents annexed thereto. Section 344 state persons entitled to receive financial statements as of right. Section 345 state the duration of time for delivery of the financial statements. Section 346-348 outlines the penalty for noncompliance with section 345 and a penalty for laying or delivering defective financial statements. Section 351 deals with the qualification of a small company, Section 352 deals with the modification of individual financial statements, while Section 353 deals with the modification of financial statements of holding company. Finally, Sections 357-369 provide for Audit of the financial statements. It provides for the appointment of auditors, qualification of auditors, auditors' report, auditors' duties and powers, remuneration of auditors, removal of auditors, auditors' right, the resignation of auditors, and the liability of auditors for negligence. From the aforementioned regulations of CAMA 1990 as amended, it is evident that SMEs poor compliance with these rules and regulation poses threat to financial reporting quality of the enterprises and also continuity of the business. Hence, this study seeks to examine the impact of compliance with companies and allied Matters Act evincing financial reporting quality on performance of SMEs in Nigeria.

\section{Literature Review}

Financial reporting interconnects routine and legitimate requirement of accounts of stewardship that enterprise managers offer to owners and other interested parties (Arabsalehi \& Velashani, 2009) for accountability. Financial reporting measures, processes, and communicates financial statistics about an identifiable economic entity (Kenter \& Pressley, 2008). Additionally, this evidence is intended to make it easier for individuals with an interest in an enterprise to make healthier decisions about that specific business. Stice and Stice (2012) opined that the goal of financial reporting is to assist interested parties in appraising an enterprise's previous performance and in projecting its forthcoming performance. The facts about historical events is envisioned to advance future processes and predictions on impending cash flows (Stice \& Stice, 2012). Obazee (2005) opined that financial reporting is the route of communicating financial information to stakeholders. This notion however deserts the purpose of financial reporting. Financial reporting is concerned with the preparation of data on the economic transactions of enterprises, focused to support differing interest groups to make informed pronouncements about the business. Thus, interest groups are numerous and their resolutions are of an extensive range (Sabari, 2004). Amid the interest groups peculiar to public sector entities are trade unions, employees, the media, civil society organizations, governments of other countries, foreign and domestic investors, tax authority, policy makers, legislators, the community, to mention but a few. Consequently, financial reporting is a means of communicating information on the accomplishments of a reporting entity to stakeholders. Thus, the quality of such financial reports is dependent on the quality of accounting principles and the resultant regulatory application of the standards (Kothari, 2000).

Talebnia, Salehi, and Kangarluei (2011) interpret financial reporting quality as the boundary in which the financial reports of an enterprise, its economic fortune, and meanings are measured over a period of time is presented fairly. Financial reporting quality is influenced by three elements, viz.; standards setters' decisions, 
accounting methods used by preparers and preparers' judgments and discretion in applying the appropriate statue (Umar, 2009). Hence, where the standards developed by accounting standards setters are based on the rigorous decision, the preparers chosen procedures and conclusions is not prejudice and the application of discretion is derived on comprehensive and consistent principles, then there will possible be high financial reporting quality. Small and Medium Enterprises being the engine of growth virtually in every economy needs to strengthened their record keeping to enhance performance and drive the economy to the next level. Financial reporting quality is vital in SMEs operations not because it enhances performance but it also improve the worthiness, goodwill and attracts ownership dilution by encouraging and luring potential investors into investment decision that is worthwhile and discourage underutilization of scarce resource.

\section{Empirical Review}

Nwobu, Samuel and Onwuelingo (2015) this study interprets the benefits of Small Scale Entrepreneurs (SSEs) engagement of accounting services from the perspective of the managers of such business enterprises in Nigeria. A survey instrument was administered to one hundred and twenty (120) respondents in Lagos State and Ogun State, Nigeria. The study observed from the prior literatures that SMEs contribute only 1 percent $(1 \%)$ of the Gross Domestic Product (GDP) in Nigeria. This low contribution in economic terms to the country may not be unconnected with the extent to which SMEs utilize accounting services. Accountants provide advisory and technical support on issues pertaining to regulation, business performance and compliance. SMEs often encounter a number of challenges, including financing, lack of credit facilities, inadequate demand for their product or services, poor exposure of management, inadequate managerial skills, overreliance on debt as a source of finance and poor record keeping, combining business funds with personal funds. These challenges may be easily overcome when businesses utilize accounting services in analyzing and monitoring their financial position, preparing documents for tax determination, as well as providing information to support production, marketing, human resources, and planning. A number of accounting services exist namely: budgeting, audit, taxation, management accounting, management consultancy and financial accounting/reporting. Budgeting helps to forecast revenues and expenditures. It also enables the business to know the actual revenues and expenditures, and eventually the differences between the forecast and actual. Internal and external audits are performed on business operations and financial statements. Tax determination entails computing the profit correctly to ascertain the tax payable. Management accounting is concerned with the provision of accounting information to managers of business enterprises. Financial reporting quality deals with the preparation of financial statements for shareholders, creditors, employees, government, and other stakeholders' consumption. The financial reporting quality does not undermine the relevance of the report, timeliness and consistency.

The study also examines the perceptions of the various owners of SMEs about the benefits of employing accounting services. The need to carry out this study arose because of the assertion of Okafor (2012) that most owner-managers in Nigeria perceive their businesses as their private affairs and hence, do not accept any responsibility to be accountable and transparent to anyone. More so, for many small firms it is expensive to obtain the services of accountants to provide accounting information and perform other accounting related functions. Accounting services provide small businesses with the relevant advisory, technical and professional support. Business owners require accountants to advise and guide them in the correct determination of profit, for better accountability and to help management achieve set goals and objectives. The findings of this study point to a large market of clients for accounting services. Small and Medium Scale Enterprises (SMEs) require professional and technical advice that accountants can give. Therefore, accounting professionals should be encouraged to explore the needs of SMEs as their active involvement in the SMEs operations could help reduce the high mortality rate of SMEs. Based on the findings of this study, accountants may also get involved in seminars and workshops to enable them understand the requirements of SMEs especially when it comes to the financial reporting quality.

Adetula et al. (2014) deliberate the readiness of SMEs in Lagos State for the adoption of International Financial Reporting Standards (IFRS) and the prospective challenges that might be faced in the adoption procedure. This study adopted a descriptive cross sectional survey design and primary method of data collection was employed. The outcome revealed that the key issue for IFRSs adoption by SMEs in Nigeria basically is to enhance financial reporting quality that will impact on the performance of the enterprises. Furthermore, the results confirmed that the IFRS for SMEs adoption procedure at this time is threatened with various challenges that might inhibit the smooth adoption and implementation of IFRS for SMEs in Nigeria. Ojeka and Mukoro (2011) opined that IFRS for SMEs enhances the comparability of information, reduce cost associated with maintaining accounting standards, presence of a complete set of accounting principles simplified for each type of entity; increased satisfaction of the needs of users of financial statements. The aforementioned improve financial reporting quality of SMEs and influence on firm performance. Work by Ramin, Yusoff, and Nasir, (2013) on Adoption of Financial and Accounting Services Outsourcing among Small Medium Enterprises discovered that Third Party Service (TPS) is an integral part of strategic positioning of an enterprise. Owing to the limited 
resources and capabilities particularly for the small and medium enterprises (SMEs). TPS outsourcing comprise the adoption of financial and accounting services outsourcing (FAO) from third party instead of internalizing these operations the firm outsourced it from an outside service provider to achieve cost advantage. The study also revealed that lack of internal capability forces SMEs to outsource some of financial functions to third party service providers. However, this is due to the availability of supply of services needed by the SMEs to the immediate outside third party service vendors. Similarly, the study also found that hiring of financial experts as a fulltime worker result in long term commitment on human resources which eventually affects the cost of human resources to the firm profitability.

\section{Materials and methods}

This study is an exploratory cross sectional survey that employed the Structural Equation Modelling (SEM) technique to overcome the limitations in the traditional multivariate method. The use of SEM technique is more appropriate than the utilization of traditional multivariate analysis owing to the fact that the assessments in SEM are based on information from the full covariance matrix. SEM technique offers comprehensible estimates of the measurement error and it is more comprehensive approach for testing construct validity, but in multivariate only exploratory assessment is examined for analyzing data. SEM technique is considered a combination of both interdependence and dependence techniques; therefore, SEM was employed in the quantitative analysis where Confirmatory and Exploratory Factor Analysis (CFA/EFA) was ascertained as a prerequisite to determine the pattern matrix for the structural equation.

\section{Exploratory and Confirmatory Factor Analysis}

Correspondingly, this study employed Exploratory Factor Analysis (EFA) and Confirmatory Factor Analysis (CFA) tied up together to comprehend shared variance of measured variables that is assumed to be attributable to a factor or latent construct. Notwithstanding this similarity, yet, EFA and CFA are theoretically and statistically different analyses. The objective of EFA is to categorize factors based on data and to exploit the amount of variance explained (Byrne, 2001). The researcher is not required to have any specific hypotheses about how many factors will arise, and what variables these factors will encompass. Per se, in divergence to EFA where all loadings are free to vary, CFA permits for the categorical constraint of definite loadings fixed to zero. EFA is occasionally reported in study when CFA would be an enhanced statistical method. It has been contended that CFA can be deterring and unfitting when used in an exploratory mode. Nevertheless, the idea that CFA is solely a "confirmatory" analysis may at times be misleading, as modification indices employed in CFA are fairly exploratory in nature. Modification indices demonstrate the improvement in model fit if specific coefficients turn out to be unconstrained. Similarly, EFA and CFA not necessarily be mutually exclusive analyses rather EFA remained contended to be a rational trail to a poor-fitting CFA model.

\section{Results and discussions.}

The data collected for the purpose of this study was screened, sorted and orderly arranged for the purpose of analysis. Therefore, central focus of this section is to present the analysis and report the findings of this study.

\section{Test of Normality}

Data normality distribution in this study was tested using the level of skewness and Kurtosis of the data either to the left, right or normally distributed. Thus, skewness designates the proportion of the distribution of data whereas Kurtosis reveal the how peak or flat is the data distribution comparative to the normal distribution (Hair et al., 2006). Conversely, the data in this research study is found to be normally distributed with no issues of skewness and kurtosis. The calculated $\mathrm{z}$ values for skewness and kurtosis is within the range of \pm 2.58 at 0.01 significance level or \pm 1.96 at 0.05 significance level. Thus, table 1 explain further the normality of the distribution of data. 
Table 1: Skewness and Kurtosis for the Research Variables

\begin{tabular}{|l|l|l|}
\hline Variables & Skewness & Kurtosis \\
\hline Book Keeping Accounting & -0.430 & -0.223 \\
\hline Period End Accounting & -0.346 & 0.163 \\
\hline Preparation of Financial Statements & -0.665 & 0.080 \\
\hline Budgeting and Forecasting & -0.301 & -0.481 \\
\hline Customer Profitability Analysis & -0.648 & 0.395 \\
\hline Financial Planning & -0.312 & 0.198 \\
\hline Internal Audit & -0.367 & -0.474 \\
\hline Interim Reporting & -0.404 & -0.236 \\
\hline Tax Related Services & -0.474 & -0.232 \\
\hline Performance & -0.433 & -0.313 \\
\hline
\end{tabular}

Source: researchers' computation 2019.

\section{Exploratory Factor Analysis}

To derive the pattern matrix in this study, data examination was conducted through EFA procedure which extracted the ten factors through their eigenvalues. The moment structures are built with the pattern matrix builder plug-in for accuracy and reliability. Consequently, EFA is performed to measure sampling adequacy and interrelationship among the variables, Bartlett's Test of Sphericity (Bartlett's Test) and Kaiser-Mayer-Olkin (KMO) was adopted and utilized. The Bartlett's Test of Sphericity (Bartlett's Test) is significant at $\mathrm{p}<0.05$ for EFA to be considered appropriate and $\mathrm{KMO} \geq 0.5$ is suitable. Dimension reduction of factors through PCFA and rotation method of Varimax with Kaiser Normalization is used in examining the measures of financial reporting quality and performance. The choice of Varimax rotation is based on the suitability of the data in obtaining valid loadings for the EFA weights for the rotated matrix applied in the structural model. However, all other rotations are equally important in conducting research but the suitability of the rotation to fit the loadings of factors is necessary.

\section{Multicolinearity}

Sample correlation matrix testing was done for multicolinearity issues. The concept of multicollinearity (or collinearity) is used to express the situation when a strong correlation is observed between two or more predictor variables.

Table 2: Collinearity Statistics

\begin{tabular}{|l|l|l|l|l|l|l|l|}
\hline \multirow{2}{*}{ Model } & \multicolumn{2}{|c|}{$\begin{array}{l}\text { 95\% Confidence } \\
\text { interval for B }\end{array}$} & \multicolumn{3}{l|}{ Correlations } & \multicolumn{2}{l|}{ Collinearity Statistics } \\
\cline { 2 - 8 } & $\begin{array}{l}\text { Lower } \\
\text { Bound }\end{array}$ & $\begin{array}{l}\text { Upper } \\
\text { Bound }\end{array}$ & Zero order & partial & part & Tolerance & VIF \\
\hline 1. (Constant) & 2.702 & 3.858 & & & & & \\
\hline Book Keeping Accounting & 0.430 & .0670 & .008 & .020 & .020 & .821 & 1.217 \\
\hline Period End Accounting & 0.346 & .0410 & -055 & .059 & .058 & .510 & 1.959 \\
\hline Preparation of Financial Statements & 0.665 & .0891 & .033 & .013 & .013 & .606 & 1.649 \\
\hline Budgeting and Forecasting & 0.301 & .1602 & .019 & .056 & .056 & .705 & 1.419 \\
\hline Customer Profitability Analysis & 0.648 & .0291 & .035 & .038 & .038 & .861 & 1.161 \\
\hline Financial Planning & 0.312 & .0930 & .009 & .007 & .007 & .819 & 1.220 \\
\hline Internal Audit & -0.367 & 0.474 & .033 & .013 & .013 & .606 & 1.704 \\
\hline Interim Reporting & 0.404 & 0.236 & .019 & .056 & .056 & .705 & 1.419 \\
\hline Tax Related Services & 0.474 & 0.232 & .035 & .038 & .038 & .861 & 1.261 \\
\hline Performance & 0.433 & 0.313 & .019 & .056 & .056 & .705 & 1.219 \\
\hline Source: researchers'
\end{tabular}

Source: researchers' computation 2019.

In table 2 above the VIF values are all below 10 then it shows no reason to worry and also all the tolerance values greater than 0.1 as it is clearly indicated in the table. Using diagnostic tests between the variables Variance Inflation Factors (VIF) and tolerance values this indicates that there is no multicollinearity in this study variables. 
Table 3 Goodness-of-Fit for initial measurement model

\begin{tabular}{|l|l|l|l|l|l|l|l|l|}
\hline \multirow{2}{*}{ MODEL } & \multicolumn{9}{|c|}{ Goodness-of-Fit Results } \\
\cline { 2 - 9 } & $\chi^{2}$ & $\chi^{2} / \mathrm{df}$ & P & GFI & TLI & NFI & CFI & RMSEA \\
\hline CFA1 & 4873.967 & 5.093 & 0.000 & 0.497 & 0.727 & 0.897 & 0.768 & 0.111 \\
\hline
\end{tabular}

Source: researchers' computation 2019.

The initial measurement model (CFA1) of this study $\left(\chi^{2}=4873.967, \chi^{2} / \mathrm{df}=5.093\right.$, GFI $=0.497$, TLI $=$ $0.727, \mathrm{NFI}=0.897, \mathrm{CFI}=0.768, \mathrm{RMSEA}=0.111)$ produced an inadequate model fit for the observed data. The overall model chi-square was 4873.967 with 957 degrees of freedom. The p-value linked with the chi-square was 0.000. However, this significant p-value contradict the empirical covariance matrix bouts in the observed data. Conversely, other model fit indices need to be examined thoroughly owing to ascertain the cause of this variation. Generally, there is the need for modification of goodness-of-fit for the model. Modification indices (MIs) dialogue box was checked with MI threshold of 30 and automatically the software pop up the modifications. After modification through the covariance of related error terms the goodness-of-fit test was re-run to obtain the result in table 4 below.

Table 4 Goodness-of-Fit for final modified measurement model

\begin{tabular}{|l|l|l|l|l|l|l|l|l|}
\hline \multirow{2}{*}{ MODEL } & \multicolumn{9}{|l|}{ Goodness-of-Fit Results } \\
\cline { 2 - 9 } & $\chi^{2}$ & $\chi^{2} / \mathrm{df}$ & P & GFI & TLI & NFI & CFI & RMSEA \\
\hline CFA2 & 1873.967 & 1.958 & 0.000 & 0.897 & 0.941 & 0.911 & 0.876 & 0.075 \\
\hline
\end{tabular}

Source: researchers' computation 2019.

The outcome in table 4 above revealed that the survey data adequately fit in the observed data. Hence, the modified final measurement model (CFA2) of this study $\left(\chi^{2}=1873.967, \chi^{2} / \mathrm{df}=1.958, \mathrm{GFI}=0.897, \mathrm{TLI}=0.941\right.$, $\mathrm{NFI}=0.911, \mathrm{CFI}=0.876$, RMSEA $=0.075)$ yield an acceptable model fit for the observed data. However, the badness-of-fit index RMSEA is slightly lower than 0.08 bench mark which indicates a tolerable value closer to the model fit indices. However, the goodness-of-fit index (GFI) was 0.897, indicating an adequate fit of the model to the observed data. Initial model normed chi-square $\left(\chi^{2} / \mathrm{df}\right)$ showed a value of 1.958 this value falls within the acceptable quotient of less than 3.0 for $\chi^{2} / \mathrm{df}$ value. The TLI and CFI are incremental fit indices and these values is approximately within the recommended level of 0.90 . Significant p-value did not show that the observed covariance matrix matches the estimated covariance matrix in the empirical data until after modification. From all indications the indices of the final model, significantly fit the base line model.

Table 5 Final Model Standardized Regression Weights, Item Reliability, Composite Reliability and Average Variance Extracted (AVE).

\begin{tabular}{|l|l|l|l|l|}
\hline Items & $\begin{array}{l}\text { Standardized } \\
\text { regression } \\
\text { weights }\end{array}$ & $\begin{array}{l}\text { Item } \\
\text { Reliability }\end{array}$ & $\begin{array}{l}\text { Composite } \\
\text { Reliability }\end{array}$ & $\begin{array}{l}\text { Average } \\
\text { Variance } \\
\text { Extracted }\end{array}$ \\
\hline Financial reporting quality & 0.932 & 0.932 & 0.901 \\
\hline Book Keeping Accounting (BKA) & 0.856 & 0.863 & & \\
\hline Period End Accounting (PEA) & 0.907 & 0.857 & & \\
\hline Preparation of Financial Statements (PFS) & 0.953 & 0.821 & & \\
\hline Budgeting and Forecasting (BAF) & 0.922 & 0.857 & & \\
\hline Customer Profitability Analysis (CPA) & 0.797 & 0.665 & & \\
\hline Financial Planning (FNP) & 0.931 & 0.865 & & \\
\hline Internal Audit (INA) & 0.989 & 0.805 & & 0.885 \\
\hline Interim Reporting (INR) & 0.901 & 0.876 & & \\
\hline Tax Related Services (TRS) & & & \\
\hline Performance & 0.931 & 0.914 & \\
\hline Production Technology (PRT) & 0.838 & 0.717 & & \\
\hline Factor Intensity (FCI) & 0.918 & 0.819 & & \\
\hline Export (EXP) & 0.894 & 0.802 & & \\
\hline Import (IMP) & 0.943 & 0.715 & & \\
\hline Source of Raw Materials (SRM) & & & \\
\hline Source: researchers' & & & \\
\hline
\end{tabular}

Source: researchers' computation 2019.

Construct Reliability (CR) Versus Variance Extracted Measures (AVE).

The outcomes in table 5 above showed that the variables of this research study significantly explained the variance in them which signifies internal consistency. This explanation is supported by the composite reliability estimate values ranging from 0.914 lowest to 0.932 highest. The cutoff value as suggested by Aubert et al., (1996) is 0.6 which is sixty percent explanation of variance in variables. Furthermore, the AVE of the indicators of the 
underlying factors are also significant. The average tolerable value of the variance in indicators is 0.5 , however all AVE in this study is beyond 0.5 ranging from 0.885 to 0.901 for financial reporting quality and SMEs performance respectively. Hence, this study concludes that the variables in the final model are reliable since over fifty percent of the variances in the observed variables were explained by the set of indicators.

\section{Discriminant Validity}

In this study discriminant validity was confirmed by AVE value, precisely whether or not it exceeds the squared inter-construct correlations linked with that construct see table 6 below

Table 6: Average Variance Extracted and Squared Correlations of Each Variable.

\begin{tabular}{|c|c|c|c|c|c|c|c|c|c|c|}
\hline & BKA & PEA & PFS & BAF & CPA & FNP & INA & INR & TRS & PRF \\
\hline BKA & 0.809 & & & & & & & & & \\
\hline PEA & 0.000 & 0.827 & & & & & & & & \\
\hline PFS & 0.076 & 0.006 & 0.692 & & & & & & & \\
\hline BAF & 0.090 & 0.002 & 0.000 & 0.803 & & & & & & \\
\hline $\mathrm{CPA}$ & 0.086 & 0.000 & 0.241 & 0.055 & 0.762 & & & & & \\
\hline FNP & 0.145 & 0.000 & 0.244 & 0.076 & 0.324 & 0.778 & & & & \\
\hline INA & 0.208 & 0.000 & 0.385 & 0.090 & 0.358 & 0.005 & 0.822 & & & \\
\hline INR & 0.266 & 0.005 & 0.358 & 0.086 & 0.250 & 0.385 & 0.420 & 0.774 & & \\
\hline TRS & 0.145 & 0.000 & 0.244 & 0.076 & 0.324 & 0.778 & 0.090 & 0.358 & 0.005 & \\
\hline PRF & 0.086 & 0.000 & 0.241 & 0.055 & 0.762 & 0.358 & 0.086 & 0.000 & 0.000 & 0.875 \\
\hline
\end{tabular}

Source: researchers' computation 2019.

Table 6, above compares the AVE of each variable and its corresponding squared correlation with other variables. Therefore, it supported that there is discriminant validity of the measurement model since the AVE is greater than the values obtained in squared correlation with other variables.

\section{Findings}

Table7: regression result.

\begin{tabular}{|c|c|c|c|c|c|c|c|}
\hline \multirow[t]{3}{*}{ Predictor Variables } & \multicolumn{6}{|c|}{ Endogenous } & \multirow[t]{3}{*}{ Remark } \\
\hline & \multicolumn{3}{|c|}{$\begin{array}{l}\text { Financial } \\
\text { Quality } \\
\left(\mathbf{R}^{2}=\mathbf{0 . 3 9}\right)\end{array}$} & \multicolumn{3}{|c|}{$\begin{array}{l}\text { Performance } \\
\left(R^{2}=0.61\right)\end{array}$} & \\
\hline & Direct & Indirect & Total & Indirect & Direct & Total & \\
\hline Book Keeping Accounting (BKA) & 0.192 & 0.000 & 0.192 & 0.000 & 0.143 & 0.143 & Supported \\
\hline Period End Accounting (PEA) & 0.274 & 0.000 & 0.274 & 0.000 & 0.205 & 0.205 & Supported \\
\hline Preparation of Financial Statements (PFS) & 0.109 & 0.000 & 0.109 & 0.000 & 0.082 & 0.082 & Supported \\
\hline Budgeting and Forecasting (BAF) & 0.047 & 0.000 & 0.047 & 0.000 & 0.035 & 0.035 & Supported \\
\hline Customer Profitability Analysis (CPA) & 0.025 & 0.000 & 0.025 & 0.000 & 0.018 & 0.018 & Supported \\
\hline Financial Planning (FNP) & 0.169 & 0.000 & 0.169 & 0.000 & 0.126 & 0.126 & Supported \\
\hline Internal Audit (INA) & 0.180 & 0.000 & 0.180 & 0.000 & 0.109 & 0.109 & Supported \\
\hline Interim Reporting (INR) & 0.047 & 0.000 & 0.047 & 0.000 & 0.047 & 0.047 & Supported \\
\hline Tax Related Services (TRS) & 0.159 & 0.000 & 0.159 & 0.000 & 0.025 & 0.025 & Supported \\
\hline Performance (PRF) & 0.000 & 0.000 & 0.000 & 0.000 & 0.875 & 0.875 & - \\
\hline
\end{tabular}

Source: researchers' computation 2019.

The path from the predictor variable BKA to the dependent variable performance was significantly different from zero at level $0.001(\beta=0.192)$ while performance is also significant in its route to financial reporting quality $(\beta=0.875)$. Therefore, the result confirmed that financial reporting quality has direct relationship with SMEs performance. Thus, Financial Reporting Quality (FRQ) impact on firm performance $(\beta=0.875)$ is significant.

The results uncover that the PEA, PFS, BAF, CPA, FNP, INA, INR, TRS is linked with performance (PRF) as $(\beta=0.274 ; \beta=0.109 ; \beta=0.047 ; \beta=0.025 ; \beta=0.169 ; \beta=0.030 ; \beta=0.047 ; \beta=0.033)$ therefore, the path from Financial Reporting Quality to Performance is significant (PRF: $\beta=0.875 ; p<0.001$ ). The probability of getting a critical ratio as large as 1.092 in absolute values are 0.143 and 0.082 respectively. In other words, the regression weight for predictor variables in the prediction of financial reporting quality is significantly different from zero at the 0.05 level (two-tailed). Consequently, Financial Reporting Quality have direct impact on Performance of SMEs in Nigeria. This study concurs with the findings in previous studies Nwobu,et al (2015); Okafor (2012); 
Adetula et al. (2014); Ezeagba (2017); Abusomwan, et al (2016) which established a direct relationship between Financial Reporting Quality and firm Performance.

\section{Conclusion and Recommendations}

The observed exogenous variables in the revised model accounted for $39 \%$ in the explanation of the total variance of the observed endogenous variable Financial Reporting Quality. Thus, the Squared Multiple Correlations (SMC) fraction between the two endogenous variables (0.39 and 0.61 refer to table 7$)$ were investigated to determine the proportion of variance that was described by the exogenous variables in the theoretical model. Hence, the overall fit of the final revised structural model. The SMEs Performance in the proposed model explained a significant volume of variance in total effect (direct) accounted up to $61 \%$ of the total variance. The proportion of variance explanation was significant bearing that there are other constraints factors not investigated by this study but yet might affect firm performance. However, this study found that regression weight for firm performance is hugely adequate in explaining the total volume variance in direct effect with FRQ. Finally, the study outcomes draw these imperative practical recommendations for SMEs owner managers. Firstly, performance decisions are driven largely by the virtual financial reporting quality involved in the record keeping. Owner managers are therefore advised to employ competent hands to handle the firm's books of account. Secondly, the study recommends that regulatory laws ought to be reinforced in order to implement compliance with laid down regulations guiding financial reporting to boost the financial reporting quality of SMEs in Nigeria and enhance their performance. Thirdly, since FRQ is having a direct and significant relationship with SMEs performance the need for enforcing compliance to statutory and regulatory framework on SMEs by SMEDAN, CBN and all other stakeholders involved in the implementation cum enforcement procedures.

\section{References}

Abusomwan, R.E., Atu, O.G., and Atu, O.O.K. (2016). Financial Reporting for Small and Medium Scale Enterprises. Igbinedion University Journal of Accounting, 2(1):11-39.

Adetula, D.T., Owolabi, F. and Onyinye, O. I. (2013). International Financial Reporting Standards (Ifrs) For Smes Adoption Process in Nigeria. European Journal of Accounting Auditing and Finance Research 2(4):33-38.

ArabSalehi, M. (2005). Trust and investment on the Iranian stock exchange: A research model. Paper presented at the $3 r$ international qualitative research convention 2005, Johor, Malaysia. Aubert, B.A., Rivard, S. and Patry, M. (2004). A transaction cost model of IT outsourcing. Information \& Management, 41(1): 921-932.

Byrne, B.M. (2001). Structural equation modelling with AMOS: Basic concepts, applications and programming. Mahwah, NJ: Erlbaum.

Companies and Allied Matters Act (CAMA) 1990 as amended 2004. The Nigerian regulatory framework for companies.

Ezeagba, C. (2017). Financial Reporting in Small and Medium Enterprises (SMEs) in Nigeria. Challenges and Options. International Journal of Academic Research in Accounting, Finance and Management Sciences, 7(1):1-10

Hair, J.F., Black, W.C., Babin, B.J., Anderson, R.E. and Tatham, R.L. (2006), Multivariate Data Analysis, $6^{\text {th }}$ ed., Prentice-Hall, Upper Saddle River, NJ.

Kanter, H. A., and Pressley, M. M. (2008). Uses of accounting information and the financial statements. Retrieved from (Kanter, H. A., \& Pressley, M. M.).

Kothari, S. P. (2000). The role of financial reporting in reducing financial risks in the market. In E. S. Rosengren, \& J. S. Jordan (eds.), Building an infrastructure for financial stability. Federal Reserve Bank of Boston Conference Series No. 44, June 2000.

NBS/SMEDAN (2016). Survey Report on Micro, Small and Medium Enterprises (MSMEs) in Nigeria. 2010 National MSMEs Collaborative Survey Between National Bureau of Statistics and Small and Medium Enterprises Development Agency of Nigeria. Central Business District FCT Abuja, Nigeria.

Nwobu, O., Faboyede, S.O., and Onwuelingo' A.T. (2015). The Role of Accounting Services in Small and Medium Scale Businesses in Nigeria. Journal of Accounting - Business and Management, 22(1): 55-63.

Ramin, A.K., Yusoff, W.F.W., and Nasir, N.K. (2013). ICTMBE 2013 2nd International Conference on Technology Management, Business and Entrepreneurship Mahkota Hotel Melaka Malaysia. 5th December 2013.

SMEDAN (2015). National Policy on Micro, Small and Medium Enterprises (MSMEs) in Nigeria. A Policy Document Prepared by Small and Medium Enterprises Development Agency of Nigeria and Approved by the Federal Executive Council. Area 11Garki Abuja, Nigeria.

Stice, J. D., Stice, E. K., Albrecht, W. S., Skousen, E. and Swain, MR. (1999). Accounting information users and use, South-Western, Ohio, 5, 5. 
Mukoro, D. and Ojeke, S. E. (2011). International Financial Reporting Standard (IFRS) And SMEs in Nigeria: A Perception of Academic. A Monthly Double-Blind Peer Reviewed Refereed Open Access International eJournal Included in the international Serial Directories 2(1).

Obazee, J.O. (2005). Standardization of Financial Reporting at the Federal, State and Local Governments Levels, The Nigerian Accountant, January/March p18.

OECD (2010), "Employment in Small and Large Firms: Where have jobs come from?" in Employment Outlook, (Paris: OECD), Sept. 